\title{
Efficacy of ultrasound-guided rectus sheath block, butorphanol for single-incision laparoscopic cholecystectomy: A prospective, randomized, clinical trial
}

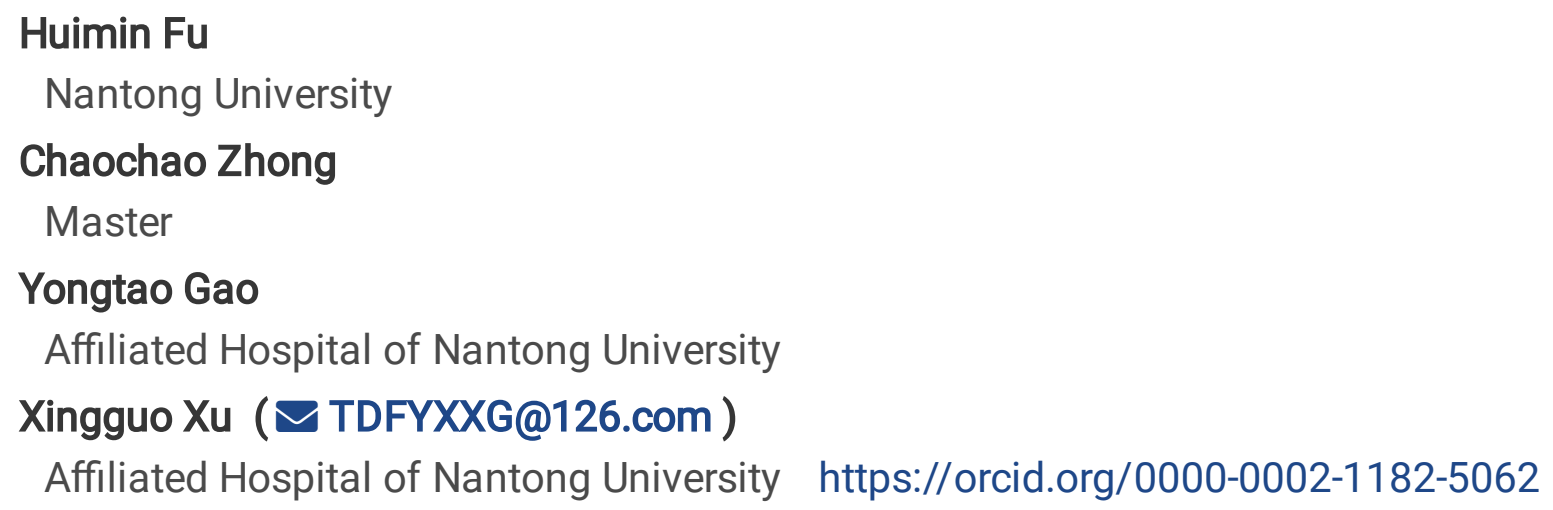

Research article

Keywords: rectus sheath block, butorphanol, single-incision laparoscopic cholecystectomy, incisional pain, visceral pain

Posted Date: December 10th, 2019

DOI: https://doi.org/10.21203/rs.2.13618/v3

License: (a) (i) This work is licensed under a Creative Commons Attribution 4.0 International License. Read Full License 


\section{Abstract}

Background: Whether rectus sheath block (RSB) combined with butorphanol can relieve incisional pain and visceral pain in patients undergoing single-incision laparoscopic cholecystectomy (SILC) remains unknown. The goal of this study was to assess the efficacy of ultrasound-guided bilateral RSB, and butorphanol for postoperative analgesia in patients undergoing SILC.Methods: All 116 patients who met the criteria were randomly divided into four groups: group I, $(n=29)$ general anaesthesia combined with patient-controlled intravenous analgesia (PCIA) (sufentanil $1 \mu \mathrm{g} / \mathrm{ml})$; group II, $(\mathrm{n}=29)$ general anaesthesia combined with PCIA (butorphanol $0.08 \mu \mathrm{g} / \mathrm{ml}$ ); group III, ( $\mathrm{n}=29)$ ultrasound-guided RSB (ropivacaine 100 $\mathrm{mg}$ ) combined with PCIA (sufentanil $1 \mu \mathrm{g} / \mathrm{ml})$; and group IV, ( $\mathrm{n}=29)$ ultrasound-guided RSB (ropivacaine $100 \mathrm{mg}$ ) combined with PCIA (butorphanol $0.08 \mu \mathrm{g} / \mathrm{ml}$ ). Outcomes included visual analogue scale (VAS) scores (0-10) of incisional pain (defined as superficial pain on the abdominal wall) and visceral pain (defined as deep, dull pain within the abdomen) at rest and during cough at 2,6,12 and $24 \mathrm{~h}$ postoperatively, the dose of butorphanol and sufentanil, the number of PCIA presses, the length of hospital stay and the incidence of postoperative adverse events. Results: Both the rest and cough incisional pain scores were lower during the first 2 and $6 \mathrm{~h}$ in group $\otimes$ than in group $\otimes(P \otimes 0.05)$. Similarly,

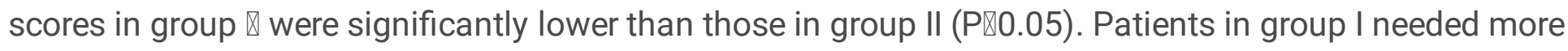
butorphanol as a rescue analgesic for pain relief than did those in group III, and patients in group IV needed less butorphanol as a rescue analgesic for pain relief than did those in group II. From the above pairwise comparisons, it is clear that groups III and IV had lower VAS scores. The VAS scores for visceral pain were lower in group II at 2, 6 and $12 \mathrm{~h}$ after surgery than in group I and lower in group IV than in group $\otimes$. Overall, ultrasound-guided RSB combined with PCIA (butorphanol $0.08 \mu \mathrm{g} / \mathrm{ml}$ ) performed the best. Conclusions: Ultrasound-guided RSB combined with butorphanol can provide sufficient pain treatment after SILC than can general anaesthesia combined with sufentanil.

\section{Background}

Cholecystolithiasis is a common and frequently occurring disease. Laparoscopic cholecystectomy is the "gold standard" for treating cholecystolithiasis. Nevertheless, progression to minimally invasive surgery has occurred from open surgery to laparoscopic surgery, single-incision surgery and robotic surgery, and surgeons have embraced the concepts of less invasiveness, less pain, earlier recovery, and shorter operations. Compared with laparoscopic cholecystectomy, single-incision laparoscopic cholecystectomy (SILC) has an outstanding cosmetic effect[1]. SILC is becoming increasingly popular[2]. It is undeniable that SILC can reduce pain[3], but postoperative pain that can arise from the incision site and visceral structures is still a major problem.

Currently, opioids are widely used for postoperative analgesia[4], and postoperative pain management has been suggested to be insufficient. On the one hand, opioids are associated with side effects, such as somnolence, postoperative nausea and vomiting (PONV), constipation, uroschesis, pruritus and respiratory depression, resulting in delayed discharge[5-7]. On the other hand, even though opioid drugs are a primary choice for the management of patients experiencing severe visceral pain[8], these 
medications cannot produce adequate pain relief, furthermore, the occurrence of visceral pain after SILC also reduces patient satisfaction. To improve postoperative pain management, multimodal analgesic regimens that include regional block and non-steroidal anti-inflammatory drugs (NSAIDS) are increasingly used. Schleich first used rectus sheath block (RSB) in 1899 to provide muscle relaxation and analgesia[9]. Formerly, RSB was not extensively used because its non-visualization leads to a high incidence of complications, such as neurologic injury, inadvertent peritoneal injury, visceral trauma, and block failure. Nevertheless, with the introduction of ultrasound into regional anaesthesia practice, tissue planes, the bowel and the spread of local anaesthetics can be seen, which may decrease accidental puncture. RSB is mainly used for postoperative analgesia after abdominal surgery. Studies have shown that $10 \mathrm{ml}$ of $0.5 \%$ ropivacaine is usually appropriate[10,11]. Recently, an increasing number of studies have emphasized the clinical value of RSB for pain relief related to midline abdominal incisions and laparoscopic and umbilical surgery[12]. Visceral pain is a complex disorder, that can be caused by mechanical traction, dilation, spasm, inflammation and chemical stimulation. Some studies have suggested that butorphanol, a $\mathrm{k}$-agonist, produces profound visceral analgesia[13].

The efficacy of RSB has been reported for postoperative analgesia after SILC[14], but the study did not thoroughly examine postoperative pain by distinguishing between incisional pain and visceral pain. Accordingly, we decided to assess the efficiency of ultrasound-guided RSB with butorphanol for incisional pain and visceral pain in patients undergoing SILC .

\section{Methods}

\section{Patients and study design}

A total of 128 patients undergoing elective SILC were enrolled in this study from February 2019 to April 2019 at the Affiliated Hospital of Nantong University. The inclusion criteria were as follows: male and female patients between 18 and 59 years of age with an American Society of Anesthesiology (ASA) score

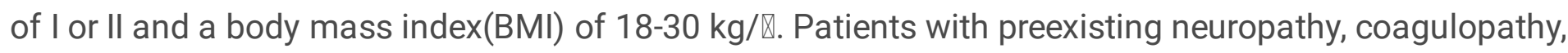
local skin infection, hepatic, renal or cardiorespiratory failure, local anaesthetic allergy, pregnancy, complications of gallstones with gallbladder perforation, diffuse peritonitis or acute pyogenic cholangitis were excluded.

The study was registered prospectively with the Chinese Clinical Trial Registry $\bigotimes$ reg no.ChiCTR1900020738) and approved by the ethics committee of Affiliated Hospital of Nantong University (approval number: 2018-K067), and written informed consent was obtained.

\section{Randomization and blinding}

All 116 patients (64 males, 52 females) scheduled for elective, SILC were randomly divided into four groups using a computer-generated random sequence concealed in consecutively numbered, opaque, sealed envelopes, which were opened on the morning of surgery. 


\section{Anaesthesia}

In a total of 116 patients, anaesthesia was induced with intravenous midazolam $0.1 \mathrm{mg} / \mathrm{kg}$, propofol 2 $\mathrm{mg} / \mathrm{kg}$, sufentanil $0.5 \mu \mathrm{g} / \mathrm{kg}$ and cisatracurium $0.15 \mathrm{mg} / \mathrm{kg}$. Anaesthesia was maintained with an infusion of $10 \mathrm{mg} / \mathrm{ml}$ propofol at $4 \mathrm{mg} / \mathrm{kg} / \mathrm{h}$ and $50 \mu \mathrm{g} / \mathrm{ml} \mathrm{remifentanil} \mathrm{at} 0.2 \mu \mathrm{g} / \mathrm{kg} / \mathrm{min}$. To ensure an adequate depth of anaesthesia, response entropy indexes were kept between 40 and 60 during the entire anaesthesia period by adjusting the rate of infusion of sufentanil and propofol.

After systemic anaesthesia was induced, in groups III and IV, the probe was transversely placed at the lateral level of the umbilicus. Using the in-plane technique, the needle was advanced until the posterior aspect of the rectus muscle was penetrated. No blood and no gas were drawn back; furthermore, a small volume of saline $(\nabla 2 \mathrm{ml})$ was initially injected to ensure that the needle tip was correctly positioned. When the needle was located between the posterior rectus muscle and posterior sheath, $20 \mathrm{ml}$ of $0.5 \%$ ropivacaine was injected bilaterally (Figure 1 ).

Patients in groups II and IV received an intravenous infusion of $1 \mathrm{mg}$ of butorphanol $30 \mathrm{~min}$ before the end of surgery. Those in groups I and III received an intravenous infusion of $10 \mu \mathrm{g}$ of sufentanil $30 \mathrm{~min}$ before the end of surgery.

Vital signs, such as blood pressure, heart rate, oxygen saturation, and electrocardiogram pattern, were recorded during the operation. The operative duration, haemorrhage volume and consumption of remifentanil and propofol were also recorded.

PCIA with a bolus dose of $2 \mu \mathrm{g}$ of sufentanil, a lock-out interval of $15 \mathrm{~min}$ and a maximum dose of $2 \mu \mathrm{g} / \mathrm{h}$ was used for routine analgesia in groups I and III. In groups II and IV, all patients received butorphanol PCIA at a background rate of $170 \mu \mathrm{g} / \mathrm{h}$ and a demand dose of $170 \mu \mathrm{g}$ every $15 \mathrm{~min}$ as rescue analgesia for postoperative pain management. During a preoperative visit, patients were adequately informed about the concept of the VAS and trained how to use PCIA.

All patients were treated by the same experienced anaesthesiologist, who specialized in ultrasoundguided regional anaesthesia and did not participate in the postoperative data collection.

\section{Measurements}

Primary outcome: In both groups, a blinded investigator who was not involved in patient recruitment or the anaesthesia procedure recorded the incisional pain at rest using a $10-\mathrm{cm}$ visual analogue scale (VAS; $0 \mathrm{~cm}=$ no pain; $10 \mathrm{~cm}=$ worst pain) at $6 \mathrm{~h}$ after the operation.

Secondary outcomes: Incisional and visceral pain at rest and during cough at 2, 12 and $24 \mathrm{~h}$ after the operation, incisional and visceral pain during cough at $6 \mathrm{~h}$ after the operation, PONV, somnolence, constipation, uroschesis, pruritus, and respiratory depression were separately assessed by a blinded observer. Butorphanol $1 \mathrm{mg}$ was administered intravenously as rescue analgesia in patients with a VAS 
score $\varangle 3$ in all groups. The blinded observer recorded the doses of butorphanol and sufentanil and the number of PCIA presses.

\section{Statistical analyses}

Statistical analysis was performed using IBM SPSS 21. Normality testing was performed using the Levene method. The patients' data are presented as the mean and standard deviation (SD) if they are normally distributed; otherwise, they are presented as the mean and interquartile range. Count data were analysed by the chi-squared ( $\chi 2)$ test. The $\chi 2$ test and Fisher's exact test were used to compare proportional data, and the Nemenyi test was used to determine differences between two groups. $P \llbracket 0.05$ was considered statistically significant. Power Analysis and Sample Size (PASS) software (NCSS, LLC, Kaysville, UT, USA) was used for the sample size calculation. An $\nabla=0.05$, a power of $90 \%$, and an expected difference in efficacy of $20 \%$ in the ultrasound-guided RSB combined with the butorphanol group were used to calculate the sample size. If the attrition rate was set at $20 \%$, a total of 72 patients (18 in each group) would be required. Thus, 116 patients (29 in each group) met our experimental needs.

\section{Results}

\section{Patients}

The study flow diagram is presented in Figure 2. A total of 128 participants were recruited into the study; eleven of them were excluded from the study, including six patients due to complications involving

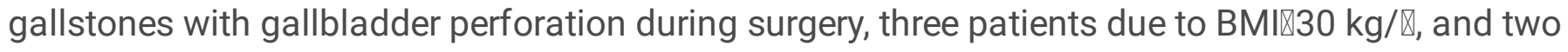
patients because of age $₫ 59$. Other patients met the inclusion criteria. Individual characteristics of patients are expressed in Table 1. There were no significant differences.

Table 1. Patient Characteristics

\begin{tabular}{|c|c|c|c|c|c|}
\hline & Group $₫(n=29)$ & Group $₫(n=29)$ & Group III $(n=29)$ & $\begin{array}{l}\text { Group } \mathbb{} \\
(n=29)\end{array}$ & P-value \\
\hline Age, mean $\pm S D, y$ & $37.2 \pm 10.9$ & $39.3 \pm 10.5$ & $38.8 \pm 11.4$ & $41.5 \pm 11.4$ & 0.521 \\
\hline $\begin{array}{l}\text { Sex, no. male/no. female } \\
\text { BMI, mean } \pm S D, k g / \mathbb{}\end{array}$ & $\begin{array}{l}17 / 12 \\
23.9 \pm 3.31\end{array}$ & $\begin{array}{l}15 / 14 \\
24.0 \pm 3.52\end{array}$ & $\begin{array}{l}16 / 13 \\
24.8 \pm 3.18\end{array}$ & $\begin{array}{l}16 / 13 \\
23.6 \pm 3.13\end{array}$ & $\begin{array}{l}0.964 \\
0.521\end{array}$ \\
\hline ASA I / $\|, n$ & $19 / 10$ & $16 / 13$ & $15 / 14$ & $14 / 15$ & 0.582 \\
\hline
\end{tabular}

The four groups showed no statistically significant differences in patients' characteristics.

BMI, body mass index; ASA, American Society of Anesthesiologists. 


\section{Postoperative pain}

There were no significant differences in the time needed for the block procedure or the quality of ultrasound images. At rest and during cough, the VAS score of incisional pain was lower during the first 2 and $6 \mathrm{~h}$ in group III than in group I ( $2.41 \pm 1.05$ vs $3.83 \pm 1.28, P \otimes 0.05 ; 4.03 \pm 0.87$ vs $4.97 \pm 1.38, P \otimes 0.05$; $1.93 \pm 1.00$ vs $2.79 \pm 1.11, P \otimes 0.05 ; 3.55 \pm 0.69$ vs $4.28 \pm 1.07, P \llbracket 0.05$ ). Similarly, the score was significantly lower in group IV than in group II ( $2.03 \pm 0.98$ vs $3.90 \pm 1.29, P \unrhd 0.05 ; 3.83 \pm 1.00$ vs $5.07 \pm 1.33$, Pख0.05; $1.83 \pm 0.89$ vs $2.76 \pm 0.99, P \llbracket 0.05 ; 3.41 \pm 0.91$ vs $4.17 \pm 1.10, P \otimes 0.05$ ). From the above pairwise comparisons, it is clear that groups III and IV had lower VAS scores. The VAS scores of visceral pain were lower in group II at 2,6 and $12 \mathrm{~h}$ after surgery than in group I $(3.90 \pm 1.14$ vs $5.21 \pm 1.21, P \llbracket 0.05 ; 3.69 \pm 0.93$ vs $5.28 \pm 1.07, P$ $\varangle 0.05 ; 3.38 \pm 0.82$ vs $4.55 \pm 1.33, P \unrhd 0.05)$ and lower in group IV than in group III ( $3.97 \pm 1.12$ vs $4.97 \pm 1.38, P \rrbracket$ $0.05 ; 3.90 \pm 1.14$ vs $5.03 \pm 1.18, P \llbracket 0.05 ; 3.41 \pm 0.91$ vs $4.00 \pm 0.96$, $P \llbracket 0.05$ ). Patients in group I needed more butorphanol as a rescue analgesic for pain relief than did those in group III $(5.57 \pm 0.81$ vs $2.45 \pm 0.99, P \square$ 0.05). Similarly, the required dose in group IV was less than that in group II $(4.90 \pm 2.02$ vs $5.17 \pm 1.07, P \rrbracket$ 0.05). The patients who were treated with less sufentanil in groups II and IV experienced less PONV. Overall, ultrasound-guided RSB combined with PCIA (butorphanol $0.08 \mu \mathrm{g} / \mathrm{ml}$ ) performed the best.

Table 2 Visual analogue scale scores at several time points.

\begin{tabular}{|c|c|c|c|c|c|c|}
\hline At rest & Time point & \multirow{2}{*}{ 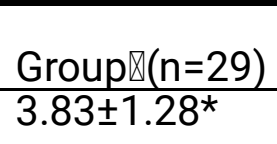 } & \multirow{2}{*}{ 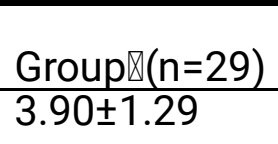 } & Group III $(n=29)$ & Group $\mathbb{\nabla}(n=29)$ & $\overline{P \text {-value }}$ \\
\hline \multirow{4}{*}{ At rest } & $2 \mathrm{~h}$ & & & $2.41 \pm 1.05$ & $2.03 \pm 0.98$ & $\mathrm{P} \bigotimes 0.05$ \\
\hline & $6 \mathrm{~h}$ & $2.79 \pm 1.11^{\star \star}$ & $2.76 \pm 0.99$ & $1.93 \pm 1.00$ & $1.83 \pm 0.89$ & $P \otimes 0.05$ \\
\hline & $12 \mathrm{~h}$ & $2.38 \pm 1.05$ & $2.10 \pm 1.14$ & $2.14 \pm 1.09$ & $1.93 \pm 0.92$ & 0.450 \\
\hline & $24 \mathrm{~h}$ & $2.03 \pm 0.82$ & $1.86 \pm 0.88$ & $1.83 \pm 0.85$ & $1.62 \pm 0.78$ & 0.309 \\
\hline During cough & $\begin{array}{l}2 \mathrm{~h} \\
6 \mathrm{~h} \\
12 \mathrm{~h} \\
24 \mathrm{~h} \\
2 \mathrm{~h} \\
6 \mathrm{~h} \\
12 \mathrm{~h} \\
24 \mathrm{~h}\end{array}$ & $\begin{array}{l}4.97 \pm 1.38 \# \\
4.28 \pm 1.07 \# \# \\
4.14 \pm 1.25 \\
3.66 \pm 0.97 \\
5.21 \pm 1.21 \\
5.28 \pm 1.07 \\
4.55 \pm 1.33 \\
2.72 \pm 0.88\end{array}$ & $\begin{array}{l}5.07 \pm 1.33 \\
4.17 \pm 1.10 \\
3.83 \pm 1.07 \\
3.55 \pm 1.09 \\
3.90 \pm 1.14 \\
3.69 \pm 0.93 \\
3.38 \pm 0.82 \\
2.55 \pm 0.74\end{array}$ & $\begin{array}{l}4.03 \pm 0.87 \\
3.55 \pm 0.69 \\
3.52 \pm 0.74 \\
3.38 \pm 0.78 \\
4.97 \pm 1.38^{\star \star \star} \\
5.03 \pm 1.18^{\star \star \star} \\
4.00 \pm 0.96 \\
2.66 \pm 0.86\end{array}$ & $\begin{array}{l}3.83 \pm 1.00 \\
3.41 \pm 0.91 \\
3.45 \pm 0.91 \\
3.48 \pm 0.83 \\
3.97 \pm 1.12 \\
3.90 \pm 1.14 \\
3.41 \pm 0.91 \\
2.28 \pm 0.80\end{array}$ & $\begin{array}{l}P \otimes 0.05 \\
P \otimes 0.05 \\
0.124 \\
0.205 \\
P \otimes 0.05 \\
P \otimes 0.05 \\
P \otimes 0.05 \\
0.176\end{array}$ \\
\hline
\end{tabular}

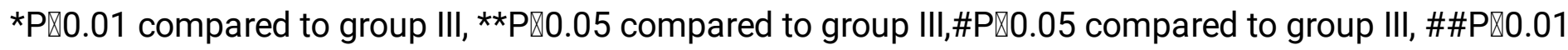
compared to group III, ${ }^{\star \star \star} \mathrm{P} \bigotimes 0.01$ compared to group $\rrbracket$.

All data are expressed as the mean $\pm S D$.

Table 3 Cumulative butorphanol and sufentanil consumption 


\begin{tabular}{llllll}
\hline & $\begin{array}{l}\text { group I } \\
(\mathrm{n}=29)\end{array}$ & $\begin{array}{c}\text { group II } \\
(\mathrm{n}=29)\end{array}$ & $\begin{array}{l}\text { group III } \\
(\mathrm{n}=29)\end{array}$ & $\begin{array}{l}\text { group IV } \\
(\mathrm{n}=29)\end{array}$ & $\begin{array}{l}\mathrm{p}- \\
\text { value }\end{array}$ \\
\hline Butorphanol consumption (mg) & $5.57 \pm 0.81^{*}$ & $5.17 \pm 1.07 \#$ & $2.45 \pm 0.99$ & $4.90 \pm 2.02$ & $\mathrm{P} \rrbracket$ \\
& & & $70.6 \pm 17.0$ & $/$ & 0.05 \\
$\begin{array}{l}\text { Sufentanil consumption in PCIA } \\
\text { (ug) }\end{array}$ & $84.8 \pm 11.0$ & $/$ & & $\begin{array}{l}\mathrm{P} \rrbracket \\
0.05\end{array}$ \\
\hline
\end{tabular}

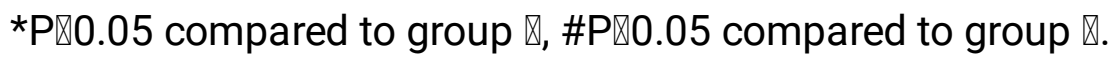

Table 4 Comparison of postoperative outcomes

\begin{tabular}{|c|c|c|c|c|c|}
\hline & 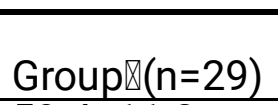 & Group $\mathbb{( n = 2 9 )}$ & $\begin{array}{l}\text { Group III } \\
(\mathrm{n}=29)\end{array}$ & $\begin{array}{l}\text { Group } \mathbb{X} \\
(\mathrm{n}=29)\end{array}$ & $\begin{array}{l}\mathrm{p}- \\
\text { value }\end{array}$ \\
\hline Duration of the operation (min) & $59.4 \pm 11.3$ & $61.4 \pm 10.8$ & $62.2 \pm 9.86$ & $61.7 \pm 11.0$ & 0.785 \\
\hline Bleeding amount $(\mathrm{ml})$ & $16.8 \pm 5.42$ & $14.2 \pm 5.54$ & $13.9 \pm 4.66$ & $15.1 \pm 5.15$ & 0.138 \\
\hline Length of stay (days) & $4.62 \pm 1.29$ & $3.97 \pm 0.94$ & $3.28 \pm 0.84$ & $2.24 \pm 0.69$ & \multirow{3}{*}{$\begin{array}{l}P \rrbracket \\
0.05 \\
P \rrbracket \\
0.05 \\
P \rrbracket \\
0.05\end{array}$} \\
\hline The numbers of PCIA & $3.55 \pm 1.09$ & $2.79 \pm 0.90$ & $1.59 \pm 1.21$ & $0.52 \pm 0.74$ & \\
\hline $\begin{array}{l}\text { Frequency of analgesic request } \\
\text { (n) }\end{array}$ & $2.45 \pm 0.99$ & $1.45 \pm 0.91$ & $1.17 \pm 0.80$ & $0.38 \pm 0.56$ & \\
\hline
\end{tabular}

The data are expressed as the mean \pm SD.

Table 5 Adverse events during the first $24 \mathrm{~h}$ after surgery.

\begin{tabular}{|c|c|c|c|c|c|}
\hline & Group $₫(n=29)$ & Group $₫(n=29)$ & Group III $(n=29)$ & Group $\varangle(n=29)$ & p-value \\
\hline PONV & $21(72.4 \rrbracket$ & $6(20.7)$ & $13(44.8)$ & $3(10.3)$ & $P \otimes 0.01$ \\
\hline Constipation, & $3(10.3 \rrbracket$ & $13.4 \rrbracket$ & $0(0.0 \rrbracket$ & $0\left(0.0 \otimes^{\prime}\right.$ & 0.632 \\
\hline Uroschesis & $5(17.2 \rrbracket$ & $0(0.0)$ & $1(3.45)$ & $2(6.90)$ & 0.057 \\
\hline Somnolence & $11(37.9)$ & $8(27.6)$ & $5(17.2)$ & $3(10.3)$ & 0.069 \\
\hline Pruritus & $1(3.45)$ & $0(0.0)$ & $1(3.45)$ & $0(0.0)$ & 0.565 \\
\hline Respiratory depression & $1(3.45)$ & $0(0.0)$ & $0(0.0)^{\prime}$ & $0(0.0)$ & 0.388 \\
\hline
\end{tabular}

Values are the number of patients (\%). PONV: postoperative nausea and vomiting

\section{Discussion}

SILC involves only a 2-cm incision into the umbilicus between the T7 and T11 intercostal nerves[15]. RSB mainly blocks the sheath nerve plexus between the rectus abdominis and posterior sheath of the rectus muscles, which is dominated by the ventral rami of the 6th to 11th intercostal nerves, providing analgesia for the peritoneum, muscle and skin involved in anterior abdominal wall incisions[9]. In the postanaesthesia care unit (PACU), we found that the range of sensory blockade was measured as a circular 
area with a radius of $5 \mathrm{~cm}$ centred on the umbilicus. RSB covers all the nerves that innervate the umbilicus, provides pre-emptive analgesia and avoids central sensitization caused by nociceptive stimuli before surgery $[16,17]$. According to our data, RSB in these patients resulted in low incisional pain scores at rest and during movement at 2 and $6 \mathrm{~h}$ after surgery, which shows that RSB can effectively relieve incisional pain in patients. The sufentanil consumption and number of PCIA presses in group III were lower than those in group I. There were no marked differences at 12 or $24 \mathrm{~h}$ after SILC among the three groups, perhaps because the efficacy of ropivacaine wears off after $12 \mathrm{~h}$. Theoretically, RSB block should provide excellent analgesia for the abdominal wall, but unfortunately, visceral pain was still evident in groups I and III. By limiting postoperative opioid use in groups II and IV, patients have fewer adverse biological reactions, but have a poor effect on visceral pain.

Visceral pain is mainly transmitted by unmyelinated $C$ fibres, is a complex sensory experience caused by trauma and inflammation, and is generally described as dull, diffuse and poorly localized[8]. Visceral pain is difficult to manage effectively, largely because the visceral sensory mechanisms and factors that contribute to the pathogenesis of visceral pain are poorly understood[18]. Visceral hyperalgesia and central sensitization have been suggested to be part of the pathophysiology[19]. At present, some studies have shown that the management of visceral pain can be achieved by activating $\mathrm{k}$-receptors[20, 21]. Opioids have been reported to have a small effect on visceral pain[8], which agrees with our data: the VAS scores of visceral pain were lower in group II at 2, 6 and $12 \mathrm{~h}$ after surgery than in group I and lower in group IV than in group III. Butorphanol, a mixed agonist-antagonist opioid, induces analgesia by opioid pathways[13]. Some studies have shown that butorphanol relieves visceral pain by indirectly suppressing cyclooxygenase activity and thus preventing prostaglandin formation in response to injury $[8,16]$. In addition, the main metabolite of butorphanol activates K-receptors and has dual effects of excitation and antagonism on $\mu$-receptors. In contrast to $\mu$-receptor agonists; (such as sufentanil), which cause side effects, such as respiratory depression, nausea and vomiting, butorphanol alleviated pruritus, and the incidence of side effects was low [13].

Compared with other methods, RSB and butorphanol are useful for multimodal postoperative pain management in SILC patients. This combination also facilitates earlier mobilization and discharge and follows the trend of enhanced recovery after surgery (ERAS). Indeed, analgesia management has a farreaching impact on the perioperative period. There are a number of limitations to this study. First, this study did not examine whether prolonged postoperative analgesia could be achieved with continuous infusion through rectus sheath catheter placement, Second, we did not study the optimal volume or dose of RSB as a postoperative analgesic method for SILC patients.

\section{Conclusions}

Our results suggest that ultrasound-guided RSB combined with butorphanol can significantly relieve postoperative incisional and visceral pain in patients undergoing SILC. Adding adjuvants to prolong the duration of local anaesthesia should be considered for in-depth study. 


\section{Abbreviations}

RSB: rectus sheath block; SILC: single-incision laparoscopic cholecystectomy; PCIA: patient controlled intravenous analgesia; VAS: visual analogue scale; PONV: postoperative nausea and vomiting; NSAIDS: non-steroidal anti-inflammatory drugs; ASA: American Society of Anesthesiology; BMI: body mass index; ERAS: enhanced recovery after surgery

\section{Declarations}

\section{Acknowledgements}

To our families and colleagues.

\section{Funding}

Not applicable

\section{Authors' contributions}

HMF carried out the studies, and drafted the manuscript. CCZ performed the statistical analysis and helped to collect the data. XGX and YTG helped to revise the manuscript. All authors read and approved the final manuscript.

\section{Availability of data and materials}

All necessary data supporting our findings have been presented within the manuscript. The datasets used and/or analysed during the current study are available from the corresponding author on reasonable request.

\section{Ethics approval and consent to participate}

Approval for this study was obtained from the ethics committee of the Affiliated Hospital of Nantong University (approval number: 2018-K067), and each patient provided a written informed consent.

\section{Consent for publication}

Not applicable

\section{Competing interests}

The authors declare that we have no competing interests.

\section{Statement}

The study adheres to CONSORT guidelines. 


\section{References}

1. Lirici MM, Tierno SM, Ponzano C: Single-incision laparoscopic cholecystectomy: does it work? A systematic review. Surg Endosc 2016, 30(10):4389-4399.

2. Omar MA, Redwan AA, Mahmoud AG: Single-incision versus 3-port laparoscopic cholecystectomy in symptomatic gallstones: A prospective randomized study. Surgery 2017, 162(1):96-103.

3. Cotirlet A, Nedelcu M, Popa E, Anghel R, Rau S, Motoc I, Tincu E: Single incision laparoscopic cholecystectomy. Chirurgia (Bucur) 2014, 109(6):769-773.

4. McNicol ED, Ferguson MC, Hudcova J: Patient controlled opioid analgesia versus non-patient controlled opioid analgesia for postoperative pain. The Cochrane database of systematic reviews 2015(6):Cd003348.

5. Webster LR: Risk Factors for Opioid-Use Disorder and Overdose. Anesthesia and analgesia 2017, 125(5):1741-1748.

6. Kane-Gill SL, Rubin EC, Smithburger PL, Buckley MS, Dasta JF: The cost of opioid-related adverse drug events. J Pain Palliat Care Pharmacother 2014, 28(3):282-293.

7. Arthur J, Hui D: Safe Opioid Use: Management of Opioid-Related Adverse Effects and Aberrant Behaviors. Hematology/oncology clinics of North America 2018, 32(3):387-403.

8. Johnson AC, Greenwood-Van Meerveld B: The Pharmacology of Visceral Pain. Advances in pharmacology (San Diego, Calif) 2016, 75:273-301.

9. Sviggum HP, Niesen AD, Sites BD, Dilger JA: Trunk blocks 101: transversus abdominis plane, ilioinguinal-iliohypogastric, and rectus sheath blocks. International anesthesiology clinics 2012, 50(1):74-92.

10. Yakoshi C, Hashimoto H, Niwa H, Kitayama M, Kudo T, Kudo M, Hirota K: [Analgesic efficacy and clinical safety of intraperitoneal instillation combined with rectus sheath block using ropivacaine for pain relief after laparoscopic gynecological surgery]. Masui The Japanese journal of anesthesiology 2014, 63(3):296-302.

11. Chung W, Yoon Y, Kim JW, Kwon SI, Yang JB, Lee KH, Yoo HJ: Comparing two different techniques of rectus sheath block after single port laparoscopic surgery in benign adnexal mass patients: Surgical versus ultrasonography guidance-A randomized, single-blind, case-controlled study. European journal of obstetrics, gynecology, and reproductive biology 2017, 217:29-33.

12. Jeong H-W, Kim CS, Choi KT, Jeong S-M, Kim D-H, Lee J-H: Preoperative versus Postoperative Rectus Sheath Block for Acute Postoperative Pain Relief after Laparoscopic Cholecystectomy: A Randomized Controlled Study. Journal of clinical medicine 2019, 8(7).

13. Tsang BK, He Z, Wongchanapai W, Ho IK, Eichhorn JH: Visceral analgesic tolerance to intrathecal butorphanol in rats. Canadian journal of anaesthesia = Journal canadien d'anesthesie 1998, 45(10):1019-1023.

14. Kamei H, Ishibashi N, Nakayama G, Hamada N, Ogata Y, Akagi Y: Ultrasound-guided rectus sheath block for single-incision laparoscopic cholecystectomy. Asian journal of endoscopic surgery 2015, 
8(2):148-152.

15. Rizzuto A, Serra R, Mignogna C, Palaia I, Zittel FU, Sacco R: Single incision laparoscopic cholecystectomy in geriatric patients. Int J Surg 2016, 35:83-87.

16. Reddi D, Curran N: Chronic pain after surgery: pathophysiology, risk factors and prevention. Postgraduate medical journal 2014, 90(1062):222-227; quiz 226.

17. Coderre TJ, Katz J, Vaccarino AL, Melzack R: Contribution of central neuroplasticity to pathological pain: review of clinical and experimental evidence. Pain 1993, 52(3):259-285.

18. Gebhart GF, Bielefeldt K: Physiology of Visceral Pain. Comprehensive Physiology 2016, 6(4):16091633.

19. Blichfeldt-Eckhardt MR, Ording H, Andersen C, Licht PB, Toft P: Early visceral pain predicts chronic pain after laparoscopic cholecystectomy. Pain 2014, 155(11):2400-2407.

20. Davis MP: Drug management of visceral pain: concepts from basic research. Pain research and treatment 2012, 2012:265605-265605.

21. Vanderah TW: Delta and Kappa Opioid Receptors as Suitable Drug Targets for Pain. Clin J Pain 2010, 26(1):S10-S15.

\section{Figures}
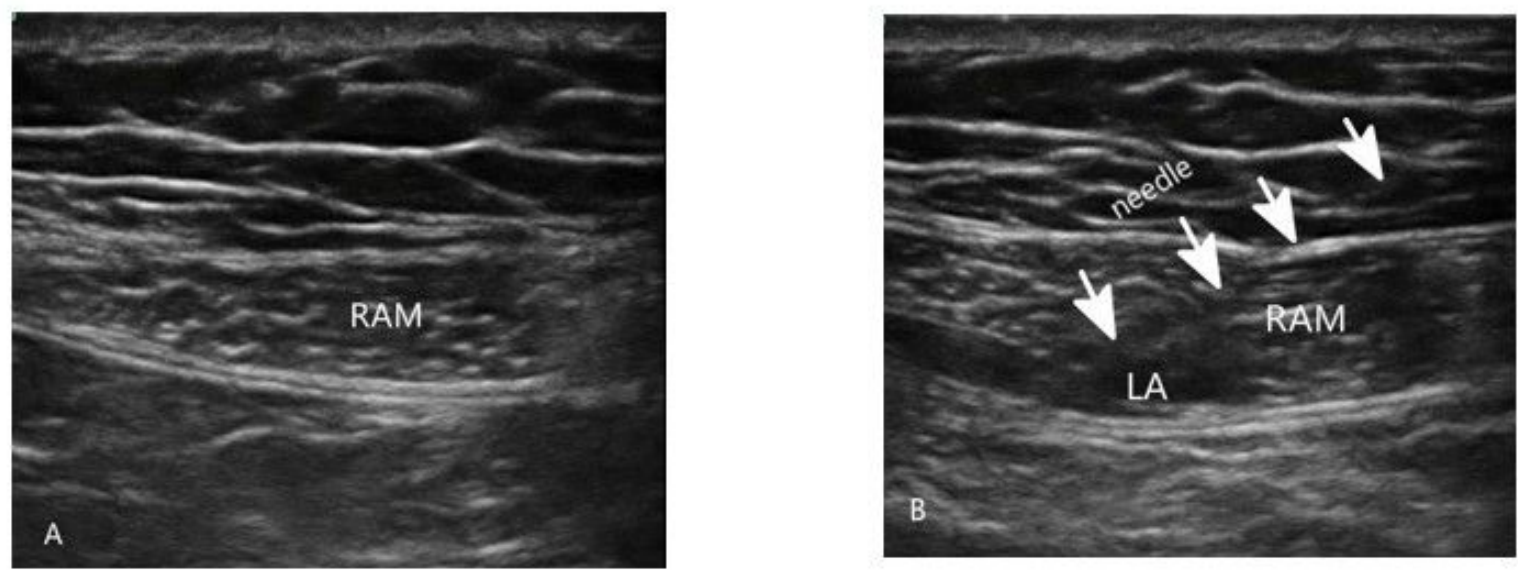

Figure 1

Ultrasound images (a) before and (b) after rectus sheath block RAM, rectus abdominal muscle, LA, local anaesthetic 